\title{
EMPREENDEDORISMO NO ENSINO FUNDAMENTAL: ESTUDO DE CASO NO MUNICÍPIO DE CORNÉLIO PROCÓPIO
}

Cristhiane Pereira De Lima

Jair De Oliveira $^{1}$

Fernanda Beatriz Costa Miranda ${ }^{1}$

Zenaide Aparecida Negrão ${ }^{1}$

${ }^{1}$ Universidade Tecnológica Federal do Paraná 


\title{
EMPREENDEDORISMO NO ENSINO FUNDAMENTAL: ESTUDO DE CASO NO MUNÍCIPIO DE CORNÉLIO PROCÓPIO
}

\begin{abstract}
Resumo: O tema deste artigo refere-se ao ensino do empreendedorismo aplicado nas séries iniciais do Ensino Fundamental e como objetivo: avaliar a importância do ensino do empreendedorismo na Educação Básica, voltada para o desenvolvimento econômico, social e sustentável. Está estruturado desta forma: (i) Surgimento da Educação Empreendedora no Brasil, Importância do Empreendedorismo nas Séries Iniciais do Ensino Fundamental, Início da Educação Empreendedora nas Escolas municipais, Metodologia de Empreendedorismo utilizada; (ii) Procedimentos Metodológicos; (iii) Análise dos resultados. Para tanto, utilizouse as metodologias de pesquisas: a bibliográfica e de estudo de caso. Foram verificados os seguintes resultados: avaliou-se o ensino do empreendedorismo no ensino fundamental no município em estudo, os resultados apontaram que o avanço no ensino empreendedor, além de proporcionar ao aluno novas possibilidades. É válido ressaltar que os resultados obtidos por meio desta pesquisa é que se considera importante o ensino do empreendedorismo no Ensino Fundamental das escolas de Cornélio Procópio.
\end{abstract}

Palavras-chave: Educação Empreendedora. Ensino Fundamental. Jovens Empreendedores

\section{Introdução}

É imperativo, que cada vez mais cedo, desperte-se a criatividade e a imaginação das crianças. Mesmo parecendo contraditório, em virtude dos avanços tecnológicos e suas consequências na transformação do mundo, isso vem deixando de ser prioridade, principalmente porque a preocupação de pais, professores e quaisquer outras pessoas responsáveis pela educação dos pequenos, faz a correspondência de futuro com trabalho, sobrevivência, emprego, qualidade de vida. Com isso realizamos os questionamentos, em que momento e de que forma eles devem receber tais informações? É possível praticar na escola atividades relacionadas ao aprendizado de empreendedorismo?

$\mathrm{Na}$ revisão bibliográfica, foi constatada ser bastante polêmica a aceitabilidade por parte de alguns autores do tema, sobre a necessidade e importância do ensino do empreendedorismo e muitos autores defendem a implementação desse conteúdo nos currículos escolares desde o ensino infantil até o universitário. Assim, o presente artigo pretende avaliar e comparar se o ensino de empreendedorismo na sala de aula nas séries iniciais do Ensino Fundamental obteve êxito ou não.

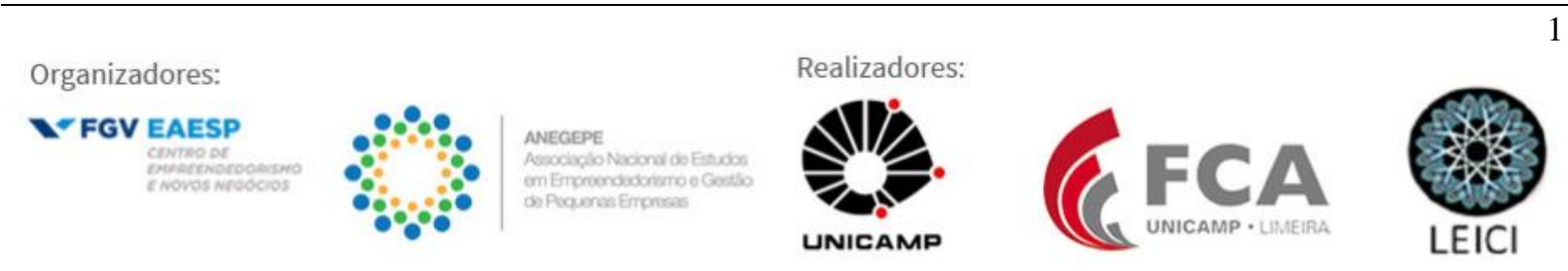


Deste modo, por meio de uma pesquisa empírica em duas escolas do município de Cornélio Procópio, iremos compará-las analisando a implementação de conteúdos que abordam princípios de empreendedorismo, refletindo porque em uma escola o resultado está sendo satisfatório e em outra não. Avaliaremos os fatores que contribuíram para um resultado satisfatório para o Ensino do Empreendedorismo.

A metodologia aplicada caracteriza este artigo como um estudo de caso e revisão bibliográfica sobre empreendedorismo na Educação, além da coleta e análise qualitativa de dados obtidos em duas escolas localizadas no munícipio de Cornélio Procópio sobre o trabalho do SEBRAE no munícipio.

\section{Fundamentação Teórica}

\subsection{Surgimento da Educação Empreendedora no Brasil.}

É um consenso, no discurso da sociedade atual, que a educação é fator preponderante quando se refere ao desenvolvimento humano, social e econômico, uma vez que o conhecimento é a base da sua formação. Porém, na transformação de ideias em atos concretos, na maioria das vezes, são encontrados inúmeros empecilhos, desde a ambiguidade das propostas, uma vez que ficam pouco visíveis a quem beneficiarão, até a discordância ideológica entre os seus criadores.

Muitos são os artigos, as dissertações e teses que defendem ou acusam a implementação da Educação Empreendedora nos currículos escolares já na fase infantil. O que se sabe, entretanto, é que com a permissão dos órgãos governamentais ou com a participação da sociedade civil empenhada numa reestruturação das camadas mais pobres da população, muitas escolas estão fazendo a experiência de despertar nos pequenos, o interesse pelo empreendedorismo.

Vale ressaltar que a escola é mais um espaço para que essa ideologia se instale e lhe atribui um valor pedagógico por representar o que é valorizado pela sociedade, geralmente a visão da elite dominante. Conforme afirma Garcia (2015):

[...] a escola sendo uma das mais importantes organizações que reproduz a ideologia dominante se apresenta como um instrumento de poder e dominação social. Para que essa dominação possa ser efetiva e legitimada socialmente, vários processos de aprendizagem ligados a internalização dos valores culturais, estéticos, políticos são apresentados para os indivíduos (Garcia, 2015. p. 36).

Portanto, a pedagogia aplicada nas escolas está diretamente vinculada ao contexto econômico, ou seja, ao capitalismo e ao neoliberalismo e a inclusão da camada marginalizada ascendendo a uma outra faixa de desenvolvimento que só é possível, como afirma (SABINO, 2010, p.3), "por meio da educação-qualificação à estrutura social consolidada da ordem burguesa".

No Brasil, o empreendedorismo aliado à educação, mesmo que timidamente, tem sua trajetória a partir das décadas de 1960 e 1970, de acordo com (Garcia, 2015), mais especificamente nos últimos anos de 1970, quando houve uma mudança na visão sobre a educação atribuindo-lhe a importância de, também, formar o cidadão.

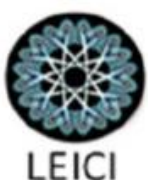


De todo modo, em 1981, a escola Superior de Administração de Empresas da Fundação Getúlio Vargas, em São Paulo oferta a disciplina "por iniciativa do professor Ronald Degen com o nome de "Novos Negócios" e foi desenvolvida com base em pesquisas com empreendedores realizadas pelo autor". (CRUZ JÚNIOR, 2006, p. 08).

Órgãos como o SEBRAE - Serviço Brasileiro de Apoio a Micro e Pequenas Empresas, Programas do Governo Federal como o Brasil Empreendedor, entre outros, são grandes incentivadores do empreendedorismo no país, entretanto a maior referência no ensino infanto-juvenil é Fernando Dolabela, com publicação de seu livro Pedagogia Empreendedora. Fernanda Góes da Silva (2015) faz uma ampla pesquisa sobre o tema, analisando muitos artigos, dissertações e teses, além de um minucioso estudo sobre os contrapontos da pedagogia empreendedora.

\subsection{Destacando a importância do empreendedorismo nas séries iniciais do Ensino Fundamental}

A discussão sobre a importância do ensino do empreendedorismo é longa e Souza (2012), inicialmente, apresenta como algo positivo o que se desenvolveu e está em andamento nos estados de Minas Gerais, São Paulo, Rio de Janeiro tanto na rede pública quanto na privada, mas os empregos de algumas palavras já denunciam a sua discordância: "imperativo, deva passar um perfil empreendedor", não fica clara sua adesão à necessidade de uma educação empreendedora que possa ser ensinada na escola, principalmente na educação básica.

Assim, questiona-se o posicionamento de Franzini (2006), quando afirma:

[...] há que se considerar, nesse caso, a subordinação da educação aos interesses utilitarista do mercado e o abandono da definição e redefinição do currículo a partir dos interesses do homem como valor em si, o que poderia, por exemplo, converter os recursos gastos com o ensino de empreendedorismo na escola para melhoria das condições do ensino de história, geografia, biologia, ciências, línguas, e demais áreas da formação básica, melhoria da formação, remuneração e carreira dos trabalhadores da educação, ou então de mais aulas de música, literatura, pintura dança. Enfim, da mais elevada expressão da cultura humana, que é a artística, e não da utilitarista educação empreendedora (SOUZA, 2012. p.87).

Ora, há que se ter uma parcimônia ao julgar a implementação de mudanças nos currículos escolares. A formação integral do homem deve passar, necessariamente, pela cultura sim, mas não se deve esquecer que os tempos mudam, as sociedades evoluem, vivemos todos num contexto global em que novas tecnologias e empreendimentos são descobertos a cada momento. Ficar à margem disso ou permitir que alguns tenham acesso à essa evolução é alijar o direito da formação, informação e desenvolvimento, que todo homem deve ter.

Cruz Júnior et al (2006), discordando de Souza (2012) confirmam a necessidade da educação empreendedora a partir de análises do abortamento de empresas, em menos de cinco anos, num levantamento feito pelo SEBRAE. Para esses autores, a lacuna, entre o sucesso e a falência de tais empreendimentos, parece estar ligada à falta de planejamento do futuro empreendedor e à ausência de práticas que poderiam ser ministradas, principalmente nos cursos de Administração, mas também uma atividade a ser incluída desde a educação básica, uma vez que, segundo esses levantamentos:

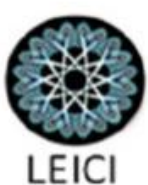


[...] além do sistema brasileiro não preparar para o empreendedorismo, destaca-se a precariedade da educação básica no país. Os empreendedores que buscam educação formal, não conseguem a capacitação necessária por falhas no próprio ensino que, na maioria das vezes, apenas apresenta as ferramentas gerenciais, mas não ensina de que forma essas ferramentas podem ser aplicadas na prática e quais são os benefícios que essa aplicação pode trazer para o empreendedor e seu negócio (CRUZ JUNIOR, p. 7, 2006).

A Educação escolar atualmente mais do que aprender conteúdos e desenvolver as habilidades do desenvolvimento, deve abranger o ser social como um todo no aspecto econômico, social e psicológico.

\subsection{Inícios da Educação Empreendedora nas Escolas municipais}

A implementação da educação empreendedora nas escolas situadas no município em estudo iniciou com a procura do SEBRAE à Secretaria Municipal de Educação de Cornélio Procópio, quando se fez a proposta de parceria para que fosse introduzido o curso Jovens Empreendedores Primeiros Passos (JEPP) nas escolas em tempo integral. Após, firmou-se um compromisso, para início das atividades.

A proposta do curso, de acordo com o SEBRAE, é a de que a educação deve atuar como transformadora desse sujeito - aluno do ensino fundamental - ao desenvolvimento das habilidades e dos comportamentos empreendedores para ampliar, promover e disseminar a educação empreendedora nas instituições de ensino por meio da oferta de conteúdos de empreendedorismo nos currículos, com o propósito de consolidar a cultura empreendedora na educação.

Por meio da Secretaria de Educação do Município de Cornélio Procópio, houve o repasse da proposta às diretoras e equipes pedagógicas das escolas que participaram do programa (JEEP). Quando foi apresentado a parceria consolidada da Secretaria de Educação com o SEBRAE. Na sequência, o projeto iniciou-se, foram realizadas orientações e capacitações dos professores, após, iniciaram-se os trabalhos em sala de aula.

\subsection{Metodologias de disseminação do Empreendedorismo aplicado no Município}

Para Corbellini e Angonese (2013), é de grande importância o papel do professor, na educação empreendedora, ser o transmissor das percepções do mundo como um todo, sendo relevante também ouvir as decisões próprias do aluno na vida dele.

Assim, utiliza-se do estudo de caso para simular métodos de decisão do empreendedor e não apenas uma simples tomada de decisão.

A educação empreendedora proposta pelo SEBRAE para o ensino fundamental incentiva os alunos a buscar o autoconhecimento, novas aprendizagens, além do espírito de coletividade. A ideia é a de que a educação deve atuar como transformadora desse sujeito e incentivá-lo à quebra de paradigmas e ao desenvolvimento das habilidades e dos comportamentos empreendedores. A solução educacional do SEBRAE para o Ensino 
Fundamental I da Educação Básica é o curso Jovens Empreendedores Primeiros Passos - JEPP, destinado a fomentar a educação e a cultura empreendedora.

O curso procura apresentar práticas de aprendizagem, considerando a autonomia do aluno para aprender e o desenvolvimento de atributos e atitudes necessários para a gerência da própria vida (pessoal, profissional e social).

Essa visão vai ao encontro dos quatro pilares da educação propostos pela UNESCO (Organização das Nações Unidas para Educação, Ciência e Cultura):

- aprender a conhecer, isto é, adquirir os instrumentos;

- aprender a fazer, para poder agir sobre o meio envolvente; aprender a viver juntos, a fim de participar e cooperar com os outros em todas as atividades humanas;

- aprender a ser, via essencial que integra as três precedentes. dessa forma, a solução, aliada a um ambiente propício à aprendizagem, favorece o envolvimento dos jovens estudantes no próprio ato de fazer, pensar e aprender. essas são características fundamentais dos comportamentos empreendedores, nos quais o estudante e o grupo em que está inserido reconhecem que suas contribuições são importantes e valorizadas.

A proposta pedagógica do JEPP (Jovens Empreendedores Primeiros Passos) para cada ano do ensino fundamental, por meio de atividades lúdicas, o ambiente da aprendizagem sensibiliza os estudantes a assumirem riscos calculados, a tomarem decisões além de terem um olhar observador para que possam identificar, ao seu redor, oportunidades de inovações, mesmo em situações desafiadoras. Em 2013, 3.162 professores de 320 escolas foram capacitados para atuarem com a proposta do JEPP em associação a 80.587 estudantes dos 9 anos do ensino fundamental em todo o Brasil. A expectativa é chegar a 696.150 estudantes do ensino fundamental no biênio 2014-2015.

\section{Procedimentos Metodológicos}

A pesquisa ocorreu com as escolas de Ensino Fundamental participante do projeto do JEEPs, localizadas em um município do norte do estado do Paraná, a fim de se investigar como é realizado o ensino do empreendedorismo no município e quais as percepções dos resultados desse programa (JEEPs). A coleta de dados foi realizada por meio de entrevista, junto a coordenadora das escolas integrais e as diretoras, conduzidas por um roteiro.

Do ponto de vista metodológico, denota-se como pesquisa descritiva, pois se caracterizam frequentemente como estudos que procuram determinar status, opiniões ou projeções futuras nas respostas obtidas e segundo Thomas e Nelson (1996, p. 2) "A sua valorização está baseada na premissa que os problemas podem ser resolvidos e as práticas podem ser melhoradas através de descrição e análise de observações objetivas e diretas".

Procedimentos da pesquisa:

1 - Entrou-se em contato com o departamento da educação do município a fim de se solicitar autorização para a coordenadora geral das escolas municipais para aplicação do questionário com a equipe pedagógica de seis escolas do município. Após a explicação dos procedimentos e objetivos da pesquisa obtivemos a liberação para a realização da mesma. 
2 - Realização do questionário, na disciplina de Empreendedorismo, do Programa de Mestrado em Ensino da UTFPR - Londrina, para a coordenadora das escolas integrais e diretoras municipais das escolas participantes do JEEP de Cornélio Procópio.

3 - Entrou-se em contato com as diretoras para aplicação do questionário da pesquisa sobre o Ensino do Empreendedorismo no município - JEEP, a fim de conhecer os procedimentos metodológicos e a forma que o JEEP é trabalhado nas escolas.

4 - O questionário aplicado foi analisado a seguir de acordo com o referencial teórico que embasou o trabalho e as respostas dos pesquisados.

5 - Foi enviado o questionário para a coordenadora das escolas integrais que prontamente respondeu todas as questões e também para seis diretoras de escolas participantes do JEEP, porém apenas duas diretoras responderam. Portanto obtivemos três respostas dos questionários.

\section{Análise dos Resultados}

A análise dos resultados foi realizada por meio das respostas de três diretoras de escolas municipais (modalidade integral) de uma cidade do norte do estado do Paraná.

A análise dos dados considerou as ordens das perguntas, as respectivas análises são apresentadas a seguir.

Na primeira pergunta: $\mathrm{O}$ que é empreendedorismo para você? Todas responderam que é a busca do autoconhecimento, fomentando novas aprendizagens, promovendo vivencias coletivas, estimulando a autonomia do aluno em aprender e estimular atributos e atitudes necessários para a vida cotidiana nos aspectos pessoais, profissionais e sociais. Podemos perceber que ao se falar em empreendedorismo as diretoras focam o conceito de empreendedorismo no aluno, sendo então o que proporciona o ensino do empreendedorismo.

Na segunda pergunta, sobre o surgimento do JEPP em Cornélio Procópio, uma das diretoras respondeu: "Através da Secretaria de Educação do Município de Cornélio Procópio houve o repasse da proposta às diretoras e equipes pedagógicas das escolas falando sobre a parceria feita entre a Educação com o Sebrae. E, a partir daí o projeto começou a se efetivar com capacitações aos professores e com o início dos trabalhos em sala de aula". O JEPP é uma proposta do SEBRAE para com as prefeituras municipais, este trabalho parte da necessidade de se formar jovens que pensem ser empreendedor em todas as áreas.

Percebe-se a aceitação dos profissionais da educação quanto a trabalhar o empreendedorismo nas escolas, visto que estes aceitaram e consideraram de forma aberta o projeto do JEEP, valorizando assim o ensino empreendedor nas séries iniciais do Ensino Fundamental.

A pergunta número três refere-se á como foi passado o conceito-objetivo do projeto. Uma das diretoras respondeu: "Através de reuniões com os coordenadores do SEBRAE $e$ capacitação com professores do SEBRAE utilizando uma metodologia clara e eficiente, com material didático de acordo com a proposta a ser aplicadas nas escolas junto aos alunos". Pode perceber que existe um treinamento constante e é um projeto que fornece capacitação tanto para a equipe pedagógica como para os professores que trabalham de maneira direta com o aluno, com isso podemos evidenciar na implementação do projeto JEEP a importância da capacitação do professor quanto a uma nova proposta de ensino, pois o SEBRAE não propôs
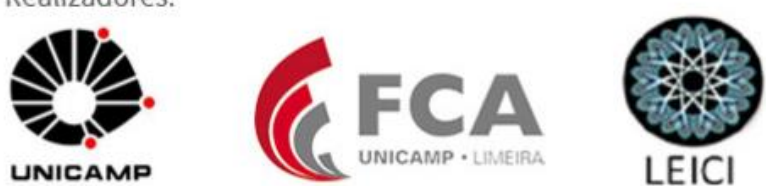
somente a aplicação do projeto nas escolas, entretanto juntamente a proposta, houve a preocupação em capacitar os professores, pois a formação continuada, como afirma Nóvoa (1991) tem entre vários objetivos melhorar a prática pedagógica do professor e por consequência a educação.

Quando foi perguntado a faixa de idade dos alunos participantes do JEEP, todas responderam que o projeto atende crianças das séries inicias do Ensino Fundamental o que caracteriza o $1^{\circ}$ ao $5^{\circ}$ ano, assim, aproximadamente a faixa etária seria de crianças de 6 a 10/11 anos, iniciando desde cedo a educação empreendedora, como afirma Lopes (2010) iniciar a educação empreendedora desde as séries iniciais até o nível superior, proporciona o desenvolvimento de habilidades como a inovação, criatividade, criticidade, conceitos relacionados ao empreendedorismo.

A próxima pergunta relaciona a forma como foi apresentado o projeto as crianças. Assim, uma das pesquisadas respondeu que o projeto foi apresentado por meio de oficinas, entrevistas, vídeos e propostas de pesquisas realizando aulas práticas e o uso de material didático proposto pelo projeto. Assim uma das depoentes citou que "É explorado materiais $e$ feito atividade praticas com o aluno fazendo este vivenciar experiências que podem mudar o futuro dele".

A sétima pergunta foi: Qual a ideia que as crianças têm de empreendedorismo antes e depois do JEPP? E uma das respostas foi: “Antes do projeto ser aplicado as crianças não tem ideia do que seja empreendedorismo, alguns acham que seja só uma forma de ganhar dinheiro. Depois do Jepp aplicado eles entendem que empreendedorismo envolve se autoconhecer, estabelecer metas/objetivos e trilhar estratégias para alcançá-los, pensar no coletivo, no bem-estar próprio e dos próximos, bem como o cuidado com o meio ambiente no qual vive. O conceito empreendedorismo se amplia na visão dos alunos". É nítido a mudança no pensar e agir das crianças após vivenciarem o JEPP. Pois hoje eles podem pensar que antes de "ganhar dinheiro" o empreendedorismo significa pensar no autoconhecimento, ou seja, no que eu quero para mim, para que eu possa ajudar o próximo.

A oitava pergunta volta-se para o envolvimento da comunidade, se ela é participativa?

A comunidade é cem por cento participativa, assim pode-se perceber que este projeto envolve mais que os alunos, mas também seus familiares e todos que estão a sua volta.

Portanto, a nona pergunta questiona se os pais, conhecem a proposta? E como reagiram ao saber que o filho tem em seu currículo uma disciplina relacionada ao empreendedorismo?

Assim, uma das pesquisadas relatou que a proposta foi divulgada por meio de uma reunião realizada com os pais dos alunos, e, além disso, durante as oficinas o professor comunica-se com os pais por meio de bilhetes no qual é pedido a colaboração deles para a realização das atividades do projeto. Com isso, ela relata que o projeto tem uma boa aceitação dos pais que compreendem a importância da educação empreendedora no ensino e aprendizagem de seus filhos.

A pergunta número onze é em relação ao aluno, no qual foi perguntado o que as diretoras acreditam que eles pensam sobre empreendedorismo no futuro e temos a resposta de uma das diretoras:

"Segundo relato dos professores as crianças esperam estabelecer metas e alcançar os objetivos pretendidos em suas vidas", e outra diretora ainda disse: "Pensam em buscar realizar
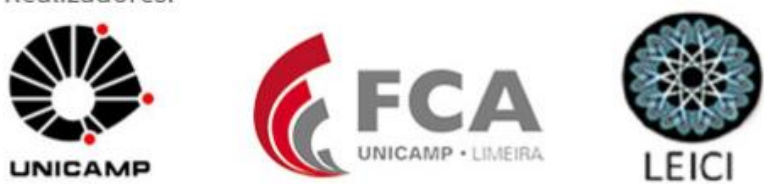
seus sonhos". É importante a vida financeira para o futuro do aluno, porém, mais que isso é importante ser um ser humano realizado.

E a pergunta doze questiona a perspectiva do diretor em relação ao futuro dos alunos, uma diretora respondeu: "Esperamos que essas crianças tenham muito sucesso em suas vidas, em todas as áreas, que elas saibam estabelecer metas e buscar alcança-las, tenham autoconfiança e saibam pensar no bem ao próximo, que busquem se conhecer e sejam completamente felizes com suas ações". Com isso, as diretoras acreditam no sucesso e empenho de todos os alunos participantes do JEPP.

Na última pergunta: Qual a contribuição que a proposta traz efetivamente para as crianças? As diretoras responderam da seguinte forma:

$A$ - "O projeto ensina as crianças a estabelecerem metas, ensina o autoconhecimento e buscar alcançar seus objetivos através de suas ações".

$B$ - "Compreensão e valorização de aspectos ligados ao financeiro e a atuação no meio social com a melhoria das formas de agir".

C - "Contribui para o desenvolvimento de competências empreendedoras nos alunos possibilitando sua inserção sustentada no mundo do trabalho".

Consoante esses pressupostos, observa-se primordial que a educação empreendedora proporciona aos estudantes a partir da experimentação e práticas empreendedoras, tanto a formação crítica, quanto a formação emancipadora no qual desenvolve habilidades que poderão ser investidas no futuro consoante com a transmissão dos conhecimentos por meio de situações reais de vivências dos alunos, "A competência é um entendimento prático de situações que se apoia em conhecimentos adquiridos e os transforma na medida em que aumenta a diversidade das situações" (ZARIFIAN, 2001, p. 72). Assim, "percebe-se com clareza o vínculo entre experiência, conhecimento e competência” (ZARIFIAN, 2001, p. 152).

\section{Considerações Finais}

Esta pesquisa se propôs comparar duas escolas e analisar se os resultados são satisfatórios, além disso avaliar por meio do depoimento da coordenadora da educação integral de as escolas com JEPP e de duas diretoras de duas escolas municipais do município de Cornélio Procópio. Por meio de um questionário as três responsáveis responderam várias perguntas e pode-se perceber o quanto o ensino do empreendedorismo, por meio do JEPP, está tendo resultados satisfatórios tanto para o aluno quanto para escola e a comunidade.

Desta forma nosso objetivo foi atingido apesar das dificuldades encontradas, que de seis escolas, com suas diretoras, apenas duas diretoras responderam o questionário. Assim a análise dos resultados foi realizada com a coordenadora de todas as escolas integrais e duas diretoras de duas escolas municipais.

É importante dar continuidade para essa pesquisa, percebendo a visão dos professores e alunos sobre o programa Jovens Empreendedores Primeiros Passos, nas escolas municipais de Cornélio Procópio.

\section{Referências:}
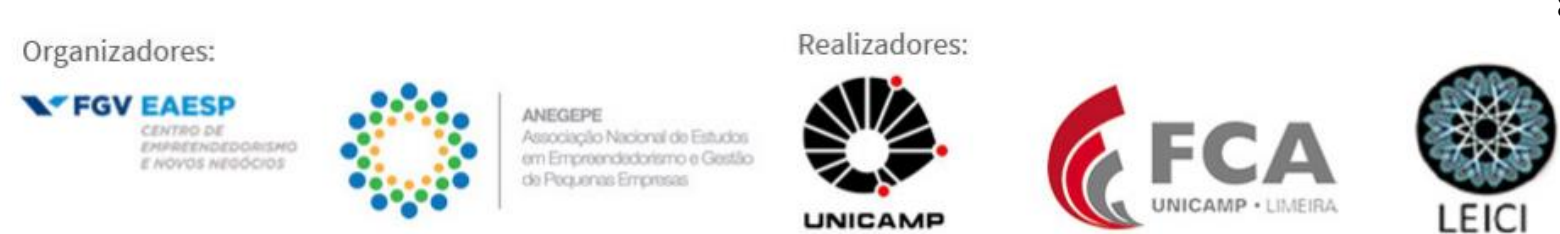
ACURCIO, M. R. B.; ANDRADE, R. C. O empreendedorismo na escola. Porto Alegre: Artmed, 2005.

DOLABELA, F. Pedagogia empreendedora. São Paulo: Cultura, 2003.

DORNELAS, J. C. A. Empreendedorismo na prática: mitos e verdades do empreendedor de sucesso. Rio de Janeiro: Elsevier, 2007.

FRAZINI, D. Q.; SELA, V. M.; SELA, F. E. R. Ensino do empreendedorismo na educação básica: estudo da metodologia "Pedagogia empreendedora" de Fernando Dolabela. In: PREVIDELLI, J. J.; SELA, V. M. (Orgs.). Empreendedorismo e educação empreendedora. Maringá: Unicorpore, 2006.

NÓVOA, Antônio. Concepções e práticas da formação contínua de professores: In: Nóvoa A. (org.). Formação contínua de professores: realidade e perspectivas. Portugal: Universidade de Aveiro, 1991.

LOPES, Rose Mary A. Educação empreendedora: conceitos, modelos e práticas. São Paulo: Elsevier, 2010.

SEBRAE disponível em: <

www.sebraepr.com.br/PortalSebrae/sebraeaz/Educa\%C3\%A7\%C3\%A3o-Empreendedora -no-Ensino-Fundamental>. Acesso em: 03.03.18

SCHUMPETER, J. A. Teoria do desenvolvimento econômico: uma investigação sobre lucros, capital, crédito, juro e o ciclo econômico. São Paulo: Nova Cultural, 1997.

ZARIFIAN, P. Objetivo competência: Por uma nova lógica. São Paulo: Atlas, 2001. 